Note

\title{
Genetic and Endocrinological Evaluations of Three 46,XX Patients with Congenital Lipoid Adrenal Hyperplasia Previously Reported as Having Presented Spontaneous Puberty
}

\author{
Ayako TANAE, Noriyuki KATSUMATA*, Naoko SATO*, Reiko HORIKAWA and Toshiaki TANAKA* \\ Division of Endocrinology and Metabolism, National Children's Hospital, Tokyo 154-8509, Japan \\ * Department of Endocrinology and Metabolism, National Children's Medical Research Center, Tokyo 154-8509, Japan
}

\begin{abstract}
Congenital lipoid adrenal hyperplasia (CLAH) is an autosomal recessive disorder characterized by impaired synthesis of adrenal and gonadal steroids. It was demonstrated that loss-of-function mutations in the steroidogenic acute regulatory protein (StAR) gene cause CLAH and that 46,XX patients with CLAH develop spontaneous puberty. We had reported that three 46,XX patients with CLAH had presented spontaneous puberty and one of the patients had developed life-threatening ovarian cysts, before the etiology of CLAH had been clarified. In the present study, we analyzed their StAR gene and demonstrated mutations. Endocrinological examinations of the patients revealed that serum LH and FSH levels and their responses to the LHRH stimulation were not exaggerated before the onset of puberty. Serum LH levels and its response to LHRH were increased during puberty, whereas serum FSH levels remained within the normal range. Serum estradiol increased after the administration of human menopausal gonadotropins in the pubertal patient, suggesting that the ovary might have another system than StAR to facilitate cholesterol transport into the mitochondria. Although the patients had menstrual cycles, they remained anovulatory, and the resultant increased secretion of $\mathrm{LH}$ was speculated to be responsible for the development of ovarian cysts.
\end{abstract}

Key words: Congenital lipoid adrenal hyperplasia, Steroidogenic acute regulatory protein, Mutation, Hypothalamic-pituitary-ovarian function

(Endocrine Journal 47: 629-634, 2000)

CONGENITAL lipoid adrenal hyperplasia (CLAH) is an autosomal recessive disorder, characterized by severe adrenal insufficiency and male pseudohermaphroiditism due to impaired synthesis of all kinds of steroids [1]. Recently it was revealed that this disease is caused by deteriorating mutations in the steroidogenic acute regulatory protein (StAR) gene [2] and that the lesions in the steroidogenic cells are

Received: March 13, 2000

Accepted: June 6, 2000

Correspondence to: Noriyuki KATSUMATA, M.D., Department of Endocrinology and Metabolism, National Children's Medical Research Center, 3-35-31 Taishido, Setagaya-ku, Tokyo 154-8509, Japan postulated to be the results of two separate events, an initial genetic loss of steroidognesis that is dependent on StAR and a subsequent loss of steroidogenesis that is independent on StAR due to cellular damage from accumulated cholesterol esters (a two-hit model of CLAH) [3]. One of the key findings leading to the two-hit model was that 46,XX CLAH patients with deteriorating mutations in the StAR gene went into spontaneous puberty, thus it was hypothesized that the fetal ovary was saved from damage by accumulating lipid droplets because it remains unstimulated until puberty [4-6]. More than ten years ago, we reported for the first time that three $46, \mathrm{XX}$ CLAH patients had entered spontaneous puberty [7]. In the present study, we report StAR gene 
Table 1. Clinical and Laboratory data at onset in 3 genetic female patients with CLAH

\begin{tabular}{|c|c|c|c|}
\hline & Patient 1 & Patient 2 & Patient 3 \\
\hline Karyotype & $46, X X$ & $46, X X$ & $46, X X$ \\
\hline Age at onset & 45 days & 30 days & 3 days \\
\hline Symptoms & hyperpigmentation & hyperpigmentation & hyperpigmentation \\
\hline at onset & poor weight gain & poor weight gain & cyanosis \\
\hline & vomiting & vomiting & vomiting \\
\hline & dehydration & dehydration & \\
\hline \multicolumn{4}{|l|}{ Serum } \\
\hline $\mathrm{Na}(\mathrm{mEq} / \mathrm{l})$ & 118 & 118 & 127 \\
\hline $\mathrm{K}(\mathrm{mEq} / \mathrm{l})$ & 7.0 & 7.0 & 12.2 \\
\hline \multicolumn{4}{|l|}{ Urine } \\
\hline 17-KGS (mg/day) & 0.35 & 0.43 & 0.05 \\
\hline 17-OHCS (mg/day) & 0.33 & 0.08 & not determined \\
\hline 17-KS (mg/day) & 0.08 & 0.18 & 0.03 \\
\hline
\end{tabular}

Table 2. Serum LH and FSH responses to LHRH stimulation

\begin{tabular}{|c|c|c|c|c|}
\hline & \multicolumn{2}{|c|}{$\mathrm{LH}(\mathrm{mIU} / \mathrm{ml})$} & \multicolumn{2}{|c|}{ FSH $(\mathrm{mIU} / \mathrm{ml})$} \\
\hline & base & peak & base & peak \\
\hline Patient 1 & 52.5 & 182.6 & 21.1 & 31.2 \\
\hline (11 years) & $(2.9-22.3)^{a)}$ & $(45.2-139.6)^{\mathrm{a})}$ & $(4.6-17.4)^{\mathrm{a})}$ & $(16.7-41.9)^{\mathrm{a})}$ \\
\hline Patient 2 & 6.2 & 13.6 & 1.9 & 12.0 \\
\hline (10 years) & $(2.3-8.7)^{b)}$ & $(12.3-36.9)^{\mathrm{b})}$ & $(2.4-10.6)^{\mathrm{b})}$ & $\left.(13.3-48.9)^{\mathrm{b}}\right)$ \\
\hline Patient 3 & 8.2 & 17.4 & 2.6 & 20.1 \\
\hline (10 years) & $(2.3-8.7)^{b)}$ & $(12.3-36.9)^{b)}$ & $\left.(2.4-10.6)^{b}\right)$ & $(13.3-48.9)^{b)}$ \\
\hline
\end{tabular}

a) Normal ranges for pubertal girls. b) Normal ranges for prepubertal girls.

mutations, and clinical and endocrinological findings in these patients.

\section{Subjects and Methods}

\section{Patients}

The clinical and laboratory findings of the patients are summarized in Tables 1, 2 and 3.

Patient 1 is a 28 -year-old genetic female, and was previously described as case 7 [7]. The elder sister of the patient, described as case 6 in the previous report [7], suffered from frequent vomiting and weight loss since 3 months of age and died at 4 months of age. Her autopsy revealed enlarged adrenal glands weighing $23 \mathrm{~g}$ (left $13 \mathrm{~g}$ and right $10 \mathrm{~g}$ ) with lipoid infiltration, focal calcification and loss of adrenal zone demarcation of the cortex. Patient 1 was the second
Table 3. Serum estradiol response to hMG stimulation

\begin{tabular}{lcc}
\hline & \multicolumn{2}{c}{ Estradiol $(\mathrm{pg} / \mathrm{ml})$} \\
\cline { 2 - 3 } & base & peak \\
\hline $\begin{array}{l}\text { Patient } 1 \\
\text { (11 years) }\end{array}$ & 59.4 & 108 \\
$\begin{array}{l}\text { Patient } 2 \\
\text { (10 years) }\end{array}$ & 18.9 & 15.7 \\
$\begin{array}{l}\text { Patient } 3 \\
\text { (10 years) }\end{array}$ & $<10$ & $<10$ \\
\hline
\end{tabular}

child of healthy unrelated Japanese parents. The patient was born by vaginal natural delivery after an uncomplicated 39-week gestation. The patient was referred to our hospital at 45 days of age because of hyperpigmentation, poor weight gain and frequent vomiting. On admission, the patient was generally pigmented and severely dehydrated. The patient had 
normal female external genitalia. Laboratory studies revealed severe salt loss. Endocrinological findings included low serum cortisol and aldosterone levels and low urinary excretion of 17-ketogenic steroids and 17-ketosteroids. Based on these findings, the patient was diagnosed as having CLAH and was successfully treated with hydrocortisone, $9 \alpha$ fludrocortisone and $\mathrm{NaCl}$. At the age of 11 years, the patient began to present rapid breast development, and breasts were Tanner stage III when gonadal function tests were performed at the same age. Serum LH was elevated basally and it responded exaggeratedly to LHRH, while basal serum FSH and its response to LHRH were almost within the normal range for pubertal females (Table 2). Serum estradiol was $59.4 \mathrm{pg} / \mathrm{ml}$ and increased to $108 \mathrm{pg} / \mathrm{ml}$ after the intramuscular administration of human menopausal gonadotropins (hMG) for 5 days (Table 3). At the age of 12 years, the patient had menarche and menstruated regularly. At the age of 15 years, the patient presented acute abdomen caused by the torsion of pedicles of bilateral large ovarian cysts, and underwent bilateral ovariectomy. Analysis of the fluid from the ovarian cysts demonstrated the presence of steroidogenesis in the ovary. Replacement therapy of estrogen and progesterone was started.

Patient 2, described as case 5 previously [7], is a 27 -year-old genetic female and is the first and only child of healthy unrelated Japanese parents. The patient was born by vaginal delivery after an uneventful 42-week gestation. The patient was referred to our hospital at 30 days of age because of hyperpigmentation and frequent vomiting. On admission, the patient had clinical and laboratory findings similar to those of Patient 1 (Table 1) and was diagnosed as having CLAH. Patient 2 was treated with hydrocortisone, $9 \alpha$-fludrocortisone and $\mathrm{NaCl}$, and did well. At the age of 10 years when the patient was still prepubertal, endocrinological examination was performed. Serum LH and its response to LHRH were compatible with those of normal prepubertal girls, and serum FSH and its response to LHRH were slightly lower than those of normal prepubertal girls (Table 2). Serum estradiol levels were low and failed to increase after the hMG administration for 5 days (Table 3). The patient presented breast development at 14 years of age, when serum LH, FSH and estradiol levels were $12.8,6.5 \mathrm{mIU} / \mathrm{ml}$, and
$<10 \mathrm{pg} / \mathrm{ml}$, respectively. The patient reported menarche at 15 years of age, when serum LH, FSH and estradiol levels were $46.2,12.6 \mathrm{mIU} / \mathrm{ml}$, and $12 \mathrm{pg} / \mathrm{ml}$, respectively. Serum estradiol increased to $46 \mathrm{pg} / \mathrm{m}$ later. By the age of 18 years, the patient had Tanner stage $\mathrm{V}$ breast and Tanner II to III pubic hair development. Although the patient has irregular 18- to 34-day menstrual cycles, the basal body temperature is not biphasic. Polycystic changes in the ovary have not been detected by repeated pelvic ultrasonography in the patient.

Patient 3, reported as case 3 previously [7], is a 26-year-old genetic female and is the first and only child of healthy unrelated Japanese parents. The patient was a product of an uneventful birth at 41 weeks of gestation. The patient manifested hyperpigmentation, cyanosis and vomiting at 3 days of life. The patient was diagnosed as having CLAH based on clinical and laboratory findings similar to those of Patients 1 and 2 (Table 1), and was successfully treated with hydrocortisone, $9 \alpha$-fludrocortisone and $\mathrm{NaCl}$. The patient was referred to our hospital at 1 year of age. At the age of 10 years, the patient was still prepubertal when endocrinological examination was carried out. Serum LH and FSH levels were within the normal prepubertal range and they increased normally after the administration of LHRH (Table 2). Serum estradiol levels were undetectable and showed no increase after stimulation with hMG for 5 days (Table 3). The patient presented breast development at 12 years of age, when serum LH, FSH and estradiol levels were 8.2, $9.4 \mathrm{mIU} / \mathrm{ml}$, and $<10 \mathrm{pg} / \mathrm{ml}$, respectively. The patient had menarche at 13 years of age, when serum LH and FSH levels were 25.3 and $10.2 \mathrm{mIU} / \mathrm{ml}$, respectively. Serum estradiol increased to $91 \mathrm{pg} / \mathrm{ml}$ later. By 17 years of age, the patient had Tanner stage IV breast and Tanner II pubic hair development. At the age of 23 years, pelvic sonography revealed a $5.4 \times 3.5 \mathrm{~cm}$ right ovary with cysts, and subsequent computed tomography confirmed bilateral ovarian cysts. Although the patient has regular 25-day menstrual cycles, the basal body temperature is not biphasic.

\section{Endocrinological evaluation}

For the LHRH stimulation test, $100 \mu \mathrm{g} / \mathrm{m}^{2}$ (maximum $100 \mu \mathrm{g}$ ) of LHRH was given as iv bolus. Serum 
LH and FSH were determined every $30 \mathrm{~min}$ for $120 \mathrm{~min}$. For the $\mathrm{hMG}$ stimulation test, $100 \mathrm{U} / \mathrm{m}^{2}$ of hMG was injected intramuscularly every day for 5 days. Serum estradiol levels were determined before the first injection and 24 hours after the last injection.

Serum LH and FSH were measured by the double antibody radioimmunoassay (RIA) method using kits from Daiichi Radioisotope Institute, Tokyo, Japan. Serum steroids were measured by specific RIAs.

\section{$D N A$ amplification and sequence analysis of the StAR gene}

The genomic DNAs of the patients and their parents were isolated from whole blood by proteinase $K$ digestion and phenol/chloroform extraction after informed consent for the genetic analysis was obtained from each subject. DNA fragments that span each of seven exons of the human StAR gene were selectively amplified using polymerase chain reaction (PCR) [8]. The oligonucleotide primers and PCR conditions were the same as described previously [9]. The amplified DNA fragments were purified by agarose gel electrophoresis, and directly sequenced in both orientations by the dideoxynucleotide chain termination method [10] using a Thermo Sequenase kit (Amersham Japan Ltd., Tokyo).

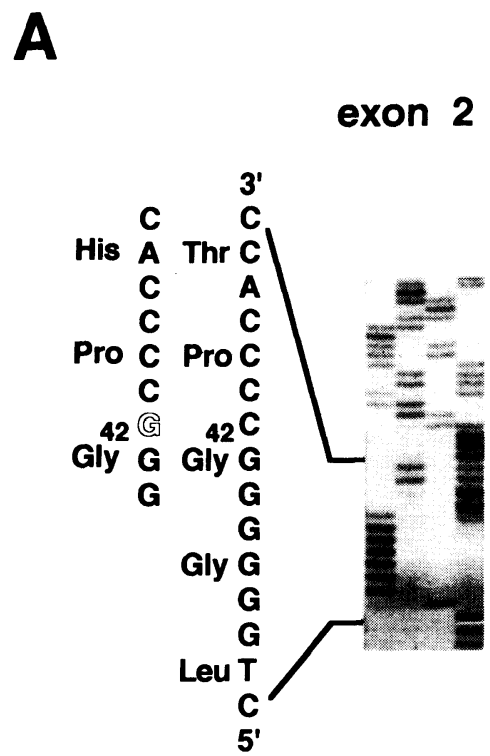

\section{Results}

The entire coding regions of the StAR gene from the patients and their parents were directly sequenced. Patients 1 and 2 were compound heterozygotes having a frameshift mutation $42 \mathrm{ins}$ in one allele and a nonsense Q258X mutation in the other (Fig. 1). Patient 3 was homozygous for the Q258X mutation (data not shown). All the patients and their parents were homozygotes for the D203A polymorphism [11].

\section{Discussion}

Two large series of genetic studies of CLAH performed by Bose et al. [3] and Nakae et al. [5] demonstrated that almost all the patients with CLAH have mutations in the StAR gene. Bose et al. also reported that there exist CLAH patients without mutations in the StAR gene [3]. Therefore we performed genetic analysis of our patients. The pathological diagnosis of CLAH was made in the elder sister of Patient 1, thus Patient 1 was highly expected to have mutations in the StAR gene. As expected, we were able to demonstrate compound heterozygous mutations in the StAR gene from Patient 1. In addition, we confirmed that Patients 2 and 3 , who were

B

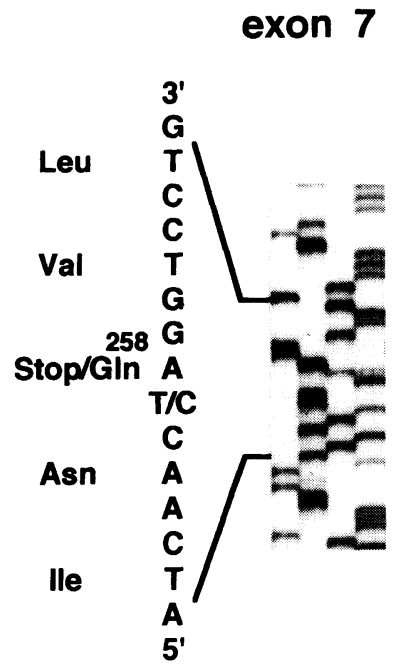

Fig. 1. Anaysis of the StAR gene from Patient 1. The patient is a compound heterozygote, having a frameshift mutation 42 insG in one allele and a nonsense mutation Q258X in the other. 
negative for family history of CLAH, have mutations in the StAR gene.

The Q258X mutation, that was detected in all three patients, was repeatedly demonstrated in Japanese and Korean patients with CLAH and was shown to totally abolish the steroidogenesis enhancing activity $[2-5,9]$. The 42 insG mutation, that was identified in Patients 1 and 2, was also previously reported in Japanese CLAH patients by others $[3,10]$. The 42insG mutation causes a shift in the amino acid reading frame of StAR messenger RNA after codon 42 , presumably resulting in premature stop at codon 46 and abolishing StAR activity, although the functional consequences of the mutation have not been studied by the functional expression study.

More than ten years after our first report [7], two groups described a total of seven 46,XX CLAH patients who underwent spontaneous puberty [4-6]. However, detailed hypothalamic-pituitary-ovarian findings were available only in one patient, in whom the LHRH stimulation tests were repeated [4]. In contrast to the report by Fujieda et al. describing an exaggerated response of LH and FSH to the LHRH stimulation in a prepubertal $46, \mathrm{XX}$ CLAH patient aged 5 years [4], we observed that serum LH and FSH responses to the LHRH stimulation were not exaggerated in Patients 2 and 3 when they were 10 years old, that was 4 years and 2 years before the onset of pubertal signs, respectively. The reason for the differences in gonadotropin responses to the LHRH stimulation in the prepubertal patients is not known, but it may be caused by the difference in the age when the patients were examined. After the onset of pubertal signs, serum LH levels were increased whereas serum FSH levels were not elevated. These findings are similar to the observations by Fujieda $e t$ al. [4].

We demonstrated that serum estradiol increased after the hMG administration in Patient 1, suggesting that the ovary might have another system than StAR to facilitate cholesterol transport into the mitochondria. In contrast, serum estradiol levels did not increase after the hMG administration in Patients 2 and 3. We interpret these responses were normal, because the patients were clinically prepubertal and showed prepubertal gonadotropin responses to the
LHRH stimulation, thus the ovaries were considered to be still functionally silent and not ready to respond to exogenous hMG administration. The unstimulated ovaries in these patients escaped damage by accumulating lipid droplets, and were able to synthesize estradiol by a StAR-independent pathway to develop secondary sexual characteristics and menstruation when pituitary gonadotropin secretions increased. These findings fit the two-hit model described by Bose et al. [3].

The development of bilateral large ovarian cysts in Patient 1 was an unexpected finding when we reported it for the first time [7], because there existed no reports on ovarian findings in pubertal CLAH patients at that time. Now it seems to be a common phenomenon for pubertal 46,XX CLAH patients because we detected bilateral ovarian cysts in Patient 3 after the onset of puberty, as did others $[4,6]$. We speculate that persistent anovulatory menstrual cycles and the resultant increased section of LH are responsible for the development of ovarian cysts, because the basal body temperature was not biphasic in our patients and no increase in serum progesterone during menstrual cycles was detected in patients reported by Fujieda et al. [4]. However, the precise mechanism for the ovarian cyst development still remains to be elucidated.

In conclusion, we demonstrated the loss-of-function mutations in the StAR gene in three 46,XX CLAH patients who had been reported to have gone into spontaneous puberty, and described hypothalamic-pituitary-ovarian findings in these patients.

\section{Acknowlegement}

The authors are grateful to Ms. Atsuko Miyokawa-Nagashima and Shoko Mikami for their technical assistance. This work was supported in part by a Grant-in-Aid for Scientific Research (C) from the Ministry of Education, Science and Culture, Japan, Grants for Pediatric Research (10C-2 and 10C-3) from the Ministry of Health and Welfare, Japan, and a Grant for Liberal Harmonious Research Promotion System from the Science and Technology Agency, Japan. 


\section{References}

1. Prader A, Siebenmann RE (1957) Nebenniereninsuffizienz bei kongenitaler Lipoihyperplasie der $\mathrm{Ne}$ bennieren. Helv Paediatr Acta 12: 569-595.

2. Lin D, Sugawara T, Straus JF III, Clark BJ, Stocco DM, Saenger P, Rogol A, Miller WL (1995) Role of steroidogenic acute regulatory protein in adrenal and gonadal steroidogenesis. Science 267: 1828-1831.

3. Bose HS, Sugawara T, Straus JF III, Miller WL (1996) The pathophysiology and genetics of congenital lipoid adrenal hyperplasia. $N$ Engl J Med 335: 1870-1878.

4. Fujieda K, Tajima $T$, Nakae J, Sageshima $S$, Tachibana K, Suwa S, Sugawara T, Straus JF III (1997) Spontaneous puberty in $46, \mathrm{XX}$ subjects with congenital lipoid adrenal hyperplasia: Ovarian steroidogenesis is spared to some extent despite in activating mutations in the steroidogenic acute regulatory protein (StAR) gene. J Clin Invest 99: 1265-1271.

5. Nakae J, Tajima T, Sugawara T, Arakane F, Hanaki K, Hotsubo T, Igarashi N, Igarashi Y, Ishii T, Koda N, Kondo T, Kohno H, Nakagawa Y, Tachibana K, Takeshima Y, Tsubouchi K, Straus JF III, Fujieda K (1997) Analysis of the steroidogenic acute regulatory protein (StAR) gene in Japanese patients with congenital lipoid adrenal hyperplasia. Hum Mol Genet 6: 571-576.

6. Bose HS, Pescovitz H, Miller WL (1997) Spontaneous feminization in a $46, \mathrm{XX}$ female patient with congen- ital lipoid adrenal hyperplasia due to homozygous frameshift mutation in the steroidogenic acute regulatory protein. $J$ Clin Endocrinol Metab 82: 1511-1515.

7. Tanae A, Miki Y, Hibi I (1988) Pubertal presentation in patients with congenital lipoid adrenal hyperplasia. Acta Paediatr Jpn 30 (Suppl): 236-238.

8. Saiki RK, Gelfand DH, Stoffel S, Scharf SJ, Higuchi R, Horn GT, Mullis KB, Erlich HA (1988) Primerdirected enzymatic amplification of DNA with a thermostable DNA polymerase. Science 239: 487-491.

9. Katsumata N, Tanae A, Shinagawa T, NagashimaMiyokawa A, Shimizu M, Yasunaga T, Tanaka T, Hibi I (1997) Detection of the missense mutation $\mathrm{A} 218 \mathrm{~V}$ in the steroidogenic acute regulatory protein gene in a Japanese patient with congenital lipoid adrenal hyperplasia. Clin Pediatr Endocrinol 6: 3337.

10. Sanger R, Nicklen S, Coulson AR (1977) DNA sequencing with chain-termination inhibitors. Proc Natl Acad Sci USA 74: 5463-5467.

11. Katsumata N, Tanae A, Shinagawa T, NagashimaMiyokawa A, Shimizu M, Yasunaga T, Tanaka T, Hibi I (1998) Novel frameshift mutation 840delA and a novel polymorphism D203A in the steroidogenic acute regulatory protein gene in a Japanese patient with congenital lipoid adrenal hyperplasia. Hum Mut Suppl 1: S304-S307. 